\title{
ELASTICIDADE-PREÇO E ELASTICIDADE-RENDA DE PASSAGEIROS POR MODO DE TRANSPORTE PARA PROJEÇÃO DE MATRIZES ORIGEM-DESTINO NACIONAL
}

\author{
Fabiano Mezadre Pompermayer ${ }^{1}$ \\ Gabriel Gouvêa Rabello² \\ Rennaly Patricio Sousa ${ }^{3}$ \\ João Gabriel de Moraes Souza ${ }^{4}$ \\ Isaque Daniel Eberhardt ${ }^{5}$
}

\section{SINOPSE}

Este texto sobre política de infraestrutura de transporte amplia o entendimento das preferências dos usuários do setor de transporte de passageiros no Brasil, ao estimar as elasticidades por modo de transporte, de forma a subsidiar a projeção da utilização futura de modos alternativos de transporte e fluxo de passageiros no Brasil. Essas projeçôes formarão as matrizes origem-destino de passageiros para o período que se iniciará em 2020 e irá até 2050.

Palavras-chave: infraestrutura; planejamento; transportes; passageiros.

\section{INTRODUÇÃO}

Um dos principais desafios da elaboração e execução de políticas públicas de transporte está na projeção da demanda futura por serviços de transporte e logística. Entender o comportamento dos usuários e a integração estratégica entre modos alternativos de transporte é essencial para compreender os riscos e benefícios das alternativas de investimento e decisões políticas em infraestrutura de transportes.

Estudo em fase final de elaboração intitulado Elasticidade-preço e elasticidade-renda de passageiros por modo de transporte para projeção de matrizes origem-destino nacional amplia o entendimento das preferências dos usuários do setor de transporte de passageiros no Brasil. Em termos práticos, este estudo servirá de base para projeçóes futuras de utilização de modos alternativos de transporte e fluxo de passageiros no Brasil.

Essas projeções formarão as matrizes origem-destino de passageiros para o período que se iniciará em 2020 e irá até 2050. As projeçôes dessas matrizes levarão em conta cenários de reformas legais e infralegais nos marcos regulatórios do setor de transporte a serem adotados no futuro próximo - sejam essas reformas de caráter parcial ou amplas.

1. Técnico de planejamento e pesquisa do Ipea (atualmente no Ministério da Economia como subsecretário de Planejamento da Infraestrutura Nacional). E-mail: <fabiano.pompermayer@ipea.gov.br>.

2. Pesquisador do Subprograma de Pesquisa para o Desenvolvimento Nacional (PNPD) na Diretoria de Estudos e Políticas Setoriais de Inovação e Infraestrutura (Diset) do Ipea. E-mail: <gabriel.rabello@ipea.gov.br>.

3. Pesquisador do PNPD na Diset/lpea.E-mail: <rennaly.sousa@ipea.gov.br>.

4. Pesquisador do PNPD na Diset//pea.E-mail: <joao.souza@ipea.gov.br>.

5. Pesquisador do PNPD na Diset/lpea.E-mail: <isaque.eberhardt@ipea.gov.br>. 
Não obstante a importância do contexto político e regulatório para o futuro dos transportes do país, a contribuição central deste estudo para a elaboração das matrizes origem-destino está nas estimativas de elasticidadespreço, elasticidades-renda e elasticidades cruzadas da demanda por diferentes modos de transporte no país.

\section{METODOLOGIA}

Com o objetivo de projetar a demanda futura pelos diferentes tipos de transportes e investigar como os usuários realizam suas escolhas, o estudo apresenta estimativas para elasticidades-preço e renda no transporte de passageiros, considerando os modos aéreo e rodoviário (automóveis e ônibus). Foram usadas, como fonte de dados, bases obtidas da Agência Nacional de Transportes Terrestres (ANTT) e da Agência Nacional de Aviação Civil (Anac), informações de tráfego de veículos fornecidas pela Associação Brasileira de Concessionárias de Rodovias (ABCR), além de informaçôes socioeconômicas extraídas do Instituto Brasileiro de Geografia e Estatística (IBGE).

Para analisar a demanda dos usuários de transporte e medir sua reação diante de eventuais mudanças no cenário econômico, foram estimadas a elasticidade-preço, a elasticidade-renda e a elasticidade cruzada, tendo sido testados três modelos de dados em painel - mínimos quadrados ordinários (MQO), efeitos aleatórios e efeitos fixos -, utilizando-se os dados citados, agregados por ano e Unidade da Federação (UF). Os principais resultados retratados neste texto são fruto das estimativas do modelo de efeitos aleatórios.

\section{RESULTADOS}

Os resultados da estimação dos dados em painel foram significativos para todos os modelos testados. Contudo, pela estatística do teste de Hausman, rejeitou-se a hipótese de que os efeitos nos pares origem-destino são adequadamente modelados pelo modelo de efeitos fixos ou MQO, sendo os modelos estimados com efeitos aleatórios os mais ajustados para os modos analisados.

O segmento de transporte rodoviário por automóveis apresentou-se elástico, em relação à renda, pela estimativa do modelo de efeitos aleatórios. Para cada $1 \%$ de variação no produto interno bruto (PIB) per capita, a demanda por esse modo de transporte cresceria 1,19\% (estimativa mensurada pela quantidade de veículos trafegados nas rodovias sob concessão ao setor privado).

Ainda em relação ao transporte por automóveis, foi avaliada a reação da demanda ao preço da gasolina principal item do custo variável de curto prazo nessa modalidade -, mas os resultados não foram estatisticamente significativos. Esse resultado poderia indicar uma insensibilidade dos usuários de automóveis ao preço da gasolina em sua decisão de utilizar ou náo esse modo de transporte.

Para o transporte rodoviário realizado por ônibus, os resultados apontaram para um efeito negativo (elasticidadepreço) no número de pagantes, dada uma variação positiva nas tarifas para o modelo de efeitos aleatórios. As estimativas pelo modelo de efeitos aleatórios mostraram uma resposta inelástica e negativa da demanda diante de aumentos do preço da passagem. Para cada 1\% de elevação no preço das passagens inter-regionais, haveria uma queda de $0,26 \%$ no número de passageiros. Uma possível explicação para esse padrão de resposta inelástica da demanda pelo aumento nos preços poderia ser explicada pela baixa presença de rotas alternativas ou ainda pela baixa ou ausente concorrência na maioria das rotas inter-regionais. Cabe ressaltar que, na maioria das rotas de pequena e média distância, o problema da baixa concorrência é ainda maior, pois existem poucas opçóes de modos de transporte (transporte aéreo e ferroviário). 
Em contraposição ao transporte rodoviário, a demanda por transporte aéreo se mostrou elástica à variação nos preços. Pelas estimativas do modelo de efeitos aleatórios, uma variação de $1 \%$ no preço das passagens aéreas induziria uma queda de $1,15 \%$ na demanda (número de passageiros).

\section{TABELA 1}

Elasticidades do volume de passageiros por modo em relação às variáveis selecionadas - resultados das estimativas para modelos em efeitos aleatórios

\begin{tabular}{lccc}
\hline Variável & Automóveis & Ônibus & Transporte aéreo \\
\hline População & $0,2272^{*}$ & $0,8897^{* *}$ & $0,9502^{* *}$ \\
PIB per capita & $1,1922^{* *}$ & $-0,2325^{* *}$ & $0,7848^{* *}$ \\
Tarifa & - & $-0,2566^{* *}$ & $-1,1512^{* *}$ \\
\hline
\end{tabular}

Elaboração dos autores.

Obs.: * $p<0,1 e^{* *} p<0,01$.

No que concerne à elasticidade-renda da demanda, as estimativas do modelo de efeitos aleatórios mostram efeitos divergentes para o transporte aéreo e rodoviário por ônibus. No primeiro caso, uma variação de $1 \%$ no PIB per capita leva a um aumento de $0,79 \%$ na demanda, demonstrando um efeito positivo do aumento da renda per capita sobre a demanda pelo modo de transporte aéreo. No segundo caso, o transporte rodoviário por ônibus apresentou uma queda de $0,23 \%$ no número de usuários em decorrência do aumento de $1 \%$ no PIB per capita, indicando um efeito negativo do aumento da renda per capita sobre a demanda do modo de transporte rodoviário por ônibus. A fim de se verificar o efeito da concorrência entre esses modos, foram estimadas as elasticidades cruzadas - ou seja, o impacto cruzado que os preços de um segmento possuem sobre a demanda do outro segmento. Os resultados encontrados foram estatisticamente não significativos.

\section{CONCLUSÕES}

Os resultados das estimaçôes de dados em painel apontaram para uma demanda inelástica aos preços para o modo rodoviário coletivo (ônibus) e uma demanda elástica para os modos aéreo e rodoviário por automóveis. O efeito cruzado analisado entre os modos rodoviário por ônibus e aéreo não foi significativo, sugerindo uma baixa inclinação dos usuários dos dois modos a substituírem um modo de transporte pelo outro em virtude de modificações de preço.

Contudo, uma eventual mudança de perfil do usuário devido a um aumento da renda sugere uma possível mudança na participaçáo dos modos no transporte de passageiros. Quando analisado o efeito renda para o modo aéreo, o efeito apresentado foi positivo, indicando que um aumento na renda leva a um amento no número de passageiros pagantes para esse modo de transporte. Para o modo de transporte rodoviário por automóveis, um aumento no PIB per capita também sugere um aumento na quantidade de veículos trafegados nas rodovias analisadas. Por sua vez, o resultado do efeito renda para o modo rodoviário por ônibus foi negativo, indicando que um aumento na renda leva a uma queda na demanda.

Uma das consequências dessa eventual queda de usuários de transporte rodoviário por ônibus seria um aumento do custo médio imposto a cada usuário, uma vez que os custos fixos seriam rateados por um menor número de passageiros. Outra consequência negativa na redução de usuários desse modo seria a queda da oferta de rotas e de horários de prestação do serviço, dificultando a sua manutenção. 
Ipea - Instituto de Pesquisa Econômica Aplicada

\section{Assessoria de Imprensa e Comunicação}

\section{EDITORIAL}

\section{Coordenação}

Reginaldo da Silva Domingos

\section{Assistente de Coordenação}

Rafael Augusto Ferreira Cardoso

\section{Supervisão}

Camilla de Miranda Mariath Gomes

Everson da Silva Moura

\section{Revisão}

Ana Clara Escórcio Xavier

Clícia Silveira Rodrigues

Idalina Barbara de Castro

Luiz Gustavo Campos de Araújo Souza

Olavo Mesquita de Carvalho

Regina Marta de Aguiar

Alice Souza Lopes (estagiária)

Amanda Ramos Marques (estagiária)

Ana Luíza Araújo Aguiar (estagiária)

Hellen Pereira de Oliveira Fonseca (estagiária)

Ingrid Verena Sampaio Cerqueira Sodré (estagiária)

Isabella Silva Queiroz da Cunha (estagiária)

Lauane Campos Souza (estagiária)

\section{Editoração}

Aeromilson Trajano de Mesquita

Bernar José Vieira

Cristiano Ferreira de Araújo

Danilo Leite de Macedo Tavares

Herllyson da Silva Souza

Jeovah Herculano Szervinsk Júnior

Leonardo Hideki Higa

\section{Capa}

Leonardo Hideki Higa

Imagens da Capa

Banco Freepik (freepik.com)

\section{Projeto Gráfico}

Renato Rodrigues Bueno

Livraria Ipea

SBS - Quadra 1 - Bloco J - Ed. BNDES, Térreo

70076-900 - Brasília - DF

Tel.: (61) 2026-5336

Correio eletrônico: livraria@ipea.gov.br 

